\title{
Measurements of local chemistry and structure in Ni(O)-YSZ composites during reduction using energy-filtered environmental TEM
}

Jeangros, Quentin; Hansen, Thomas Willum; Wagner, Jakob Birkedal; Dunin-Borkowski, Rafal E.; Hebert, Cecile; Van herle, Jan; Hessler-Wyser, Aicha

Published in:

Chemical Communications

Link to article, DOI:

$10.1039 / \mathrm{c3cc} 46682 \mathrm{e}$

Publication date:

2014

Document Version

Publisher's PDF, also known as Version of record

Link back to DTU Orbit

Citation $(A P A)$ :

Jeangros, Q., Hansen, T. W., Wagner, J. B., Dunin-Borkowski, R. E., Hebert, C., Van herle, J., \& Hessler-Wyser, A. (2014). Measurements of local chemistry and structure in Ni(O)-YSZ composites during reduction using energy-filtered environmental TEM. Chemical Communications, 50(15), 1808-1810.

https://doi.org/10.1039/c3cc46682e

\section{General rights}

Copyright and moral rights for the publications made accessible in the public portal are retained by the authors and/or other copyright owners and it is a condition of accessing publications that users recognise and abide by the legal requirements associated with these rights.

- Users may download and print one copy of any publication from the public portal for the purpose of private study or research.

- You may not further distribute the material or use it for any profit-making activity or commercial gain

- You may freely distribute the URL identifying the publication in the public portal 


\section{ChemComm}

\section{COMMUNICATION}

\section{Measurements of local chemistry and structure in $\mathrm{Ni}(\mathrm{O})-\mathrm{YSZ}$ composites during reduction using energy-filtered environmental TEM}

Cite this: Chem. Commun., 2014 50,1808

Received 1st September 2013,

Accepted 9th December 2013

DOI: $10.1039 /$ c3cc46682e

www.rsc.org/chemcomm

\author{
Quentin Jeangros, ${ }^{\star a}$ Thomas W. Hansen, ${ }^{\mathrm{b}}$ Jakob B. Wagner, ${ }^{\mathrm{b}}$ \\ Rafal E. Dunin-Borkowski, ${ }^{c}$ Cécile Hébert, ${ }^{a}$ Jan Van herle ${ }^{d}$ and \\ Aïcha Hessler-Wyser ${ }^{a}$
}

Energy-filtered transmission electron microscopy images are acquired during the reduction of a NiO-YSZ composite in $\mathrm{H}_{2}$ up to $600{ }^{\circ} \mathrm{C}$. Temperature-resolved quantitative information about both chemistry and structure is extracted with $\mathrm{nm}$ spatial resolution from the data, paving the way for the development of detailed reduction models.

Nickel-yttria-stabilized zirconia (Ni-YSZ) composites are widely employed as anode structures in solid oxide fuel cells (SOFCs). ${ }^{1}$ In such applications, the anode operates at $\sim 700-800{ }^{\circ} \mathrm{C}$ in a reducing atmosphere and acts as a fuel oxidation catalyst, a hydrocarbon reforming catalyst, a current collector and often as the mechanical supporting layer of the whole fuel cell. For ease of manufacturing, nickel oxide (NiO) particles are usually first co-sintered with YSZ and then reduced to Ni during the first operation of the cell, while the YSZ backbone remains chemically unchanged. This anode activation process should ideally yield connected and intersecting networks of YSZ, Ni and voids, in order to guarantee high electrochemical efficiency. A full understanding of both chemical and structural changes induced by the reduction of $\mathrm{NiO}$ at the nanometre scale is therefore essential. Both aspects can be addressed at this length scale under gas reaction conditions and at elevated temperature using an environmental transmission electron microscope (ETEM) that is equipped with a post-column imaging filter. ${ }^{2}$ The objective of the present communication is twofold; first to complement initial results that qualitatively address the activation of the Ni-YSZ cermet $^{3 a}$ with a quantitative structural and chemical assessment of the process using energy-filtered transmission electron microscopy (EFTEM) and second to demonstrate the feasibility of using such an analytical technique to capture spatially localized chemical and nanostructural information with the specimen held at high temperature in a gas atmosphere.

\footnotetext{
${ }^{a}$ Interdisciplinary Centre for Electron Microscopy, Ecole Polytechnique Fédérale de Lausanne, Lausanne, Switzerland. E-mail: quentin.jeangros@epfl.ch; Fax: +41 2169344 01; Tel: +41216936813

${ }^{b}$ Center for Electron Nanoscopy, Technical University of Denmark, Kgs. Lyngby, Denmark

${ }^{c}$ Ernst Ruska-Centre for Microscopy and Spectroscopy with Electrons and Peter Grünberg Institute, Jülich Research Centre, Jülich, Germany

${ }^{d}$ Fuelmat Group, Ecole Polytechnique Fédérale de Lausanne, Lausanne, Switzerland
}

A standard NiO-YSZ anode was prepared for ETEM observations using a conventional focused ion beam (FIB) lift-out technique in a dual beam FIB/SEM Zeiss NVision 40 CrossBeam workstation. Reduction of the NiO-YSZ sample was performed in situ in a differentially pumped FEI Titan 80-300 ETEM equipped with a post-column imaging filter using a Gatan double tilt 652 heating holder. ${ }^{2 b}$ The microscope was operated at $300 \mathrm{kV}$ at an electron dose rate of $10^{3} \mathrm{e}^{-} \mathrm{nm}^{-2} \mathrm{~s}^{-1}$, which was constant throughout the entire experiment. $\mathrm{H}_{2}$ was introduced in the column at a flow rate of $2 \mathrm{ml}_{\mathrm{N}} \min ^{-1}$, resulting in a pressure of $1.3 \mathrm{mbar}$ around the sample. A temperature ramp with an overall rate of $2{ }^{\circ} \mathrm{C} \min ^{-1}$ was used between 300 and $604{ }^{\circ} \mathrm{C}$ to study the evolution of the system as a function of temperature. The temperature was manually increased in steps of $16{ }^{\circ} \mathrm{C}$ over a duration of 2 minutes and then maintained constant for 6 minutes to perform structural and chemical measurements. Each acquisition sequence included the following brightfield TEM images (collection semi-angle of $6.8 \mathrm{mrad}$ ): one unfiltered image $I_{t}$, one filtered zero-loss image $I_{0}$ and three images $I_{\text {pre-edge } 1}$, $I_{\text {pre-edge } 2}$ and $I_{\text {post-edge }}$ at energy loss onsets of $472 \mathrm{eV}, 502 \mathrm{eV}$ and $532 \mathrm{eV}$, respectively (with a slit width of $30 \mathrm{eV}$ and an acquisition time of $40 \mathrm{~s}$ ). All of the recorded images were aligned by crosscorrelation after filtering using a Sobel operator. ${ }^{4 a}$ Images $I_{t}$ and $I_{0}$ were used to construct a $t / \lambda$ thickness map (where $t$ is the thickness in $\mathrm{nm}$ and $\lambda$ is the total-inelastic mean free path, estimated here to be $127 \mathrm{~nm}$ for $\mathrm{Ni}$ and $155 \mathrm{~nm}$ for $\mathrm{NiO}^{4 b} \dagger$ ). Images $I_{\text {pre-edge } 1}, I_{\text {pre-edge } 2}$ and $I_{\text {post-edge }}$ were processed to obtain elemental maps of the oxygen $\mathrm{K}$ edge $(532 \mathrm{eV})$ using the conventional three window method, ${ }^{4 c}$ whereby the two $I_{\text {pre-edge }}$ images were used to extrapolate a power law background that was subtracted from the $I_{\text {postedge }}$ image that contains the oxygen $\mathrm{K}$ edge signal. Oxygen and $t / \lambda$ maps were initially acquired at $30{ }^{\circ} \mathrm{C}$ ( $\mathrm{NiO}$ reference) and then at $604{ }^{\circ} \mathrm{C}$, $130 \mathrm{~min}$ after the end of the ramp (Ni reference; full reduction of Ni regions confirmed using electron energy-loss spectroscopy, EELS). As the ceramic phase is structurally and chemically stable at these temperatures, the YSZ backbone in each oxygen and thickness map was used as an invariant reference to monitor intensity changes in the adjacent evolving $\mathrm{Ni}(\mathrm{O})$ phase. Each thickness/oxygen map was divided by the total number of counts in its YSZ phase to remove 

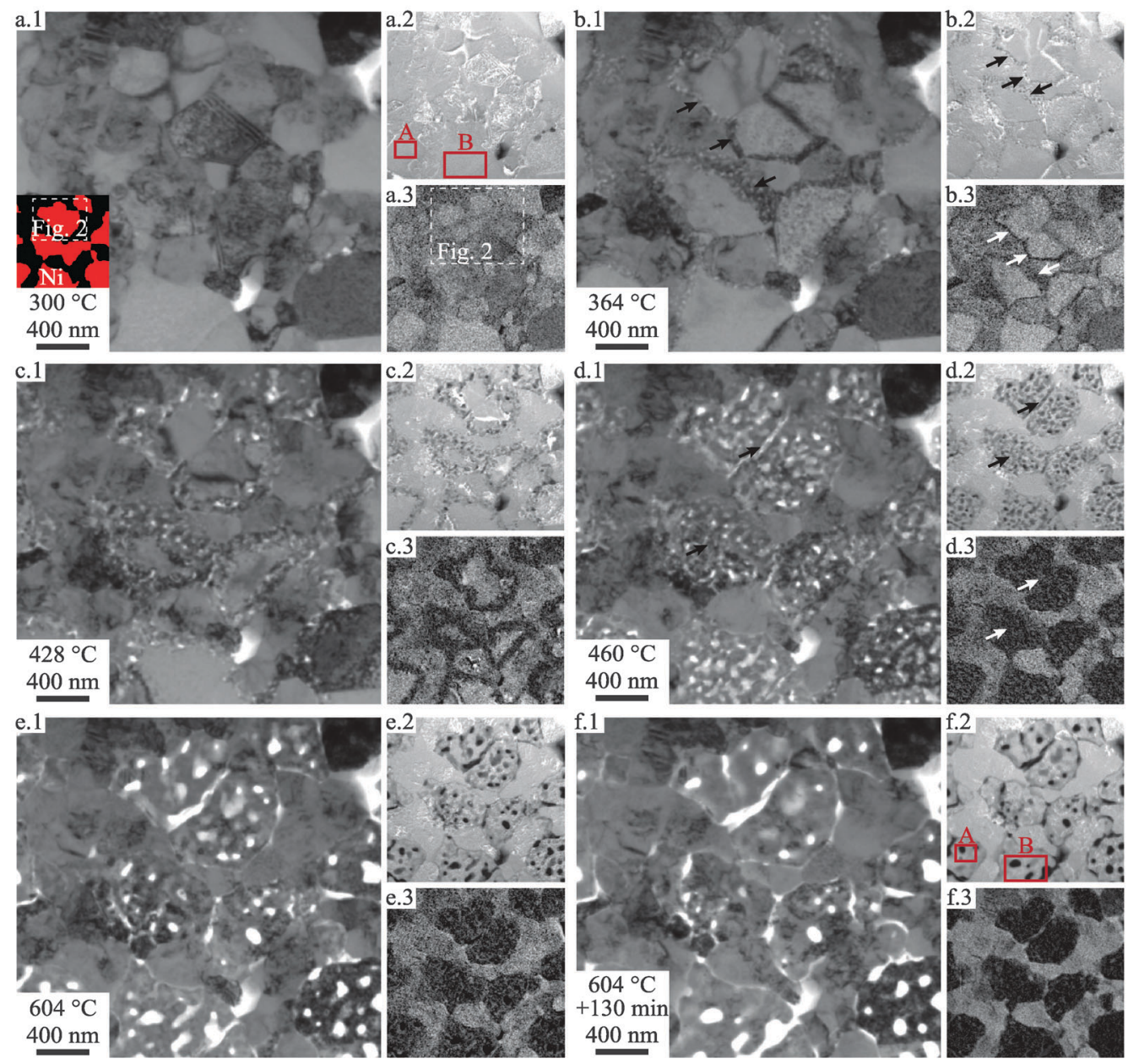

Fig. 1 (a-e) Selection of (1) bright-field TEM images and corresponding (2) $t / \lambda$ and (3) oxygen maps acquired during ramping at $2{ }^{\circ} \mathrm{C}$ min ${ }^{-1}$ in 1.3 mbar of $\mathrm{H}_{2}$. The images in (f) were acquired 130 minutes after reaching $604{ }^{\circ} \mathrm{C}$ (full reduction of Ni confirmed by EELS). An EFTEM nickel map is shown as an inset in a.1 to highlight the position of the $\mathrm{Ni}(\mathrm{O})$ grains as well as the region of interest investigated in Fig. 2 (also shown in a.3). The intensities of the regions that are labelled $A$ and $B$ in $a .2$ and f.2 were used to monitor reduction-induced thickness changes. Arrows indicate initiation of the reaction at the $\mathrm{Ni}(\mathrm{O})-\mathrm{YSZ}$ interfaces in (b) and at the free surface of $\mathrm{NiO}$ in (d).

intensity offsets and to yield thickness/oxygen maps with comparable intensities. The results could then be analysed quantitatively, by comparing them to the experimental $\mathrm{NiO}$ and Ni references.

Fig. 1 shows a sequence of unfiltered bright-field TEM images acquired at different temperatures, alongside corresponding $t / \lambda$ and oxygen maps (after normalization using the total intensity in the YSZ backbone). The first changes in $\mathrm{NiO}$ are observed at grain boundaries with the YSZ phase just below $350{ }^{\circ} \mathrm{C}$, as in preliminary observations, ${ }^{3 a}$ presumably as a result of oxygen ion transfer from the NiO to the YSZ. This process creates oxygen vacancies in the NiO close to each interface, and as these sites dissociate $\mathrm{H}_{2}$ efficiently, the reduction reaction is triggered. ${ }^{3 b}$ Oxygen depletion in the $\mathrm{Ni}(\mathrm{O})$ regions close to the YSZ phase is observed directly in the oxygen maps, while the thickness maps demonstrate void formation in the $\mathrm{Ni}(\mathrm{O})$ regions at the interfaces, in order to compensate the volume shrinkage that takes place during reduction (see arrows in Fig. 1b). The reaction fronts proceed towards the centres of the $\mathrm{Ni}(\mathrm{O})$ grains up to a temperature of at least $428{ }^{\circ} \mathrm{C}$. At higher temperatures, the free surface of the $\mathrm{Ni}(\mathrm{O})$ grains reduces directly (see arrows in Fig. $1 \mathrm{~d}$ ).
Ni grains and internal voids are observed to sinter at $604{ }^{\circ} \mathrm{C}$. The acquisition of energy-filtered images allows quantitative thickness and chemical information to be determined. Volume changes induced by the complete reduction of $\mathrm{NiO}$ to $\mathrm{Ni}$ can be calculated directly using the initial unreacted $t / \lambda$ map and the final fully reduced $t / \lambda$ image by multiplying the intensity in either the NiO or the Ni regions by $\lambda_{\mathrm{NiO}}$ and $\lambda_{\mathrm{Ni}}$, respectively. As diffraction effects alter the overall intensity, regions that do not exhibit these contrast features, such as those labelled A and B in Fig. 1a.2 and f.2, were analysed. Although the accuracy of the estimation of $\lambda$ will also affect the results, the volume shrinkage resulting from $\mathrm{NiO}$ reduction to Ni measured in regions $\mathrm{A}$ and $\mathrm{B}$ is $-40 \%$ and $-42 \%$, respectively, which are close to the theoretical value of $-41.6 \%{ }^{1 b}$ and thus considered to be representative.

Fig. 2 shows a sequence of oxygen maps, which focuses on one $\mathrm{Ni}(\mathrm{O})$ grain surrounded by YSZ. The chemical information at the position of each pixel evolves as a function of temperature and time. In order to obtain statistically relevant information, $\mathrm{Ni}(\mathrm{O})$ pixels that exhibit the same structural 


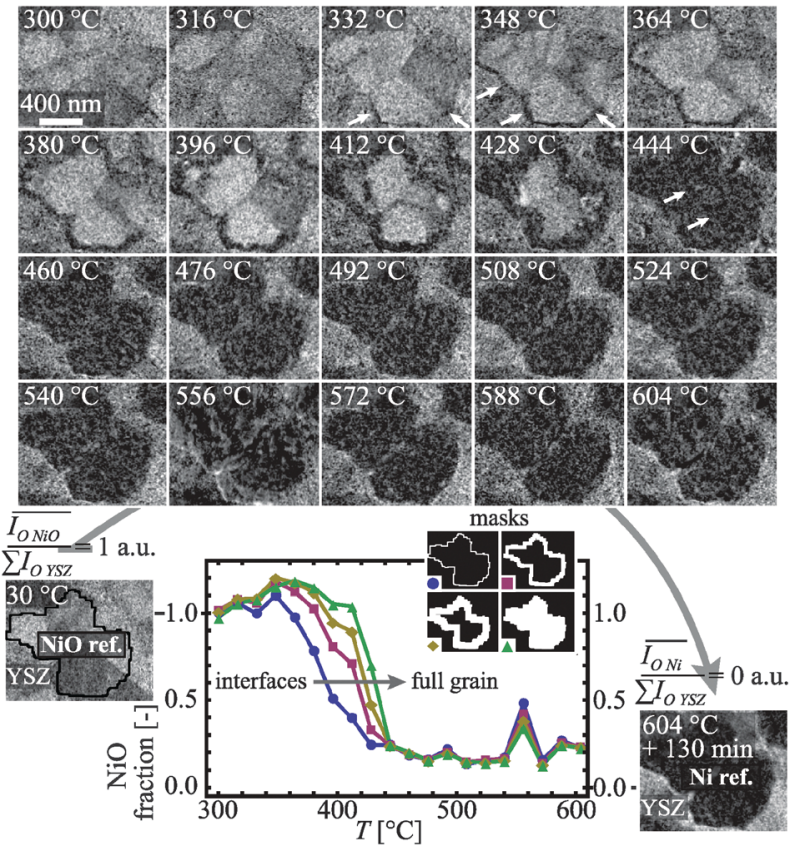

Fig. 2 Sequence of oxygen maps showing the evolution of one $\mathrm{Ni}(\mathrm{O})$ grain during reduction (see Fig. 1a for the position of the chosen grain). Arrows mark the initiation of reduction at the NiO interfaces with YSZ and then at the $\mathrm{NiO}$ free surface. The mean intensity in 4 different masks starting at the YSZ interfaces, progressively selecting the entire $\mathrm{Ni}(\mathrm{O})$ grain, was normalized using the $\mathrm{NiO}$ and $\mathrm{Ni}$ experimental references to yield the fraction of $\mathrm{NiO}$ as a function of temperature. The increase in the $\mathrm{NiO}$ fraction at $360{ }^{\circ} \mathrm{C}$ is induced by bend contours (diffraction), while the peak at $556{ }^{\circ} \mathrm{C}$ is due to drift during acquisition.

features (interfaces with YSZ or bulk material) were selected by masking the map accordingly. The mean intensity in these regions was evaluated and normalized using the corresponding mean values obtained from the $\mathrm{NiO}$ and $\mathrm{Ni}$ references to yield the reaction kinetics, i.e., the fraction of $\mathrm{NiO}$ as a function of temperature (see the plot in Fig. 2). The mean fraction of $\mathrm{NiO}$ at the YSZ interfaces is observed to gradually decrease over the temperature range of $\sim 100{ }^{\circ} \mathrm{C}\left(348{ }^{\circ} \mathrm{C}\right.$ to $\left.444{ }^{\circ} \mathrm{C}\right)$. The mean amount of $\mathrm{NiO}$ in the entire grain decreases by a few percent from $348{ }^{\circ} \mathrm{C}$ to $412{ }^{\circ} \mathrm{C}$ due to the reactions at the interfaces and then sharply from $412{ }^{\circ} \mathrm{C}$ to $444{ }^{\circ} \mathrm{C}$ as a result of free surface reduction. As the $\mathrm{NiO}$ fraction is then constant for the four different masks at a given temperature, the degree of reduction of the grain appears to be homogenous from $444{ }^{\circ} \mathrm{C}$ to $604{ }^{\circ} \mathrm{C}$. A NiO fraction of $\sim 20 \%$ is left unreduced at the end of the ramp, which is consistent with quantitative EELS experiments performed during similar reduction of NiO particles. $^{2 a}$ Future work will involve the use of solid-state kinetic models to describe the progress of the reaction as a function of temperature, as in ref. $2 \mathrm{a}$, with the exception that the chemical information is now localized spatially at the pixel per nm scale. This methodology should enable the assessment of any correlation between $\mathrm{Ni}(\mathrm{O})$ grain size and reaction kinetics, an effect not studied here.

Different factors affect the acquisition and interpretation of reliable in situ data during reaction at high temperature. As only thin samples can be investigated using TEM, surface-related effects are amplified with respect to the processes that occur in the bulk.
Sample preparation may also influence ETEM observations. For example, FIB-induced gallium implantation and surface amorphization effects on NiO reduction are not yet fully understood. Recently-developed low-voltage argon ion milling systems with focused ion beams should remove such artefacts more efficiently in future experiments. A comparison of unprocessed raw powders and FIB-prepared samples that have the same chemistry appears to be essential to investigate sample preparation effects. Thermal drift decreases the quality of energy-filtered images acquired over long exposure times. Although the use of a stainless steel grid reduced the overall drift of the sample, a low heating rate of $2{ }^{\circ} \mathrm{C} \min ^{-1}$ was still required to acquire interpretable energy-filtered images and thus to capture the reaction. The recent introduction of MEMSbased heating holders decreases thermally induced drift significantly and thus allows the acquisition of reliable data during ramping at higher heating rates. However, the geometry of such a holder is not optimized for studies of FIB-prepared lamellae or low-voltage argon cleaning. Electron beam-induced artefacts must also be assessed in detail. ${ }^{2 a}$ While all of these effects must be considered, energy-filtered imaging in a gas atmosphere at high temperature still has the ability to provide quantitative new insights into solid-gas reactions with nm spatial resolution.

The acquisition of energy-filtered images during the reduction of a NiO-YSZ composite at different temperatures has allowed information to be obtained about both chemistry (using $\mathrm{O} \mathrm{K}$ edge images) and structure (using total-inelastic mean free path images) with $\mathrm{nm}$ spatial resolution. The use of the YSZ backbone as an invariant reference throughout the experiment allowed the extraction of data about the evolution of the $\mathrm{Ni}(\mathrm{O})$ phase, which could be related quantitatively to $\mathrm{NiO}$ and Ni references. While relative changes in thickness provide information about the three-dimensional evolution of the system, oxygen maps allow the extraction of reaction kinetics localized at the nm scale. Local differences in the reaction rate as a result of structural and chemical features can be investigated in detail using this methodology.

\section{Notes and references}

$\dagger$ While a measured value of $E_{\mathrm{m}}$ (an average energy-loss value) was used for $\mathrm{NiO}(19.8 \mathrm{eV})$ to yield $\lambda_{\mathrm{NiO}}$, the effective atomic number of $\mathrm{Ni}$ was used to estimate $E_{\mathrm{m}}\left(25.2 \mathrm{eV}\right.$ ) and in turn $\lambda_{\mathrm{Ni}}$ (see ch. 5 of ref. $4 \mathrm{~b}$ ).

1 (a) S. C. Singhal and K. Kendall, High temperature solid oxide fuel cellfundamentals, design and applications, Elsevier, Oxford, 2003; (b) A. Faes, A. Nakajo, A. Hessler-Wyser, D. Dubois, A. Brisse, S. Modena and J. Van herle, J. Power Sources, 2009, 193, 55-64.

2 (a) Q. Jeangros, T. W. Hansen, J. B. Wagner, C. D. Damsgaard, R. E. Dunin-Borkowski, C. Hébert, J. Van herle and A. Hessler-Wyser, J. Mater. Sci., 2013, 48, 2893-2907; (b) T. W. Hansen, J. B. Wagner and R. E. Dunin-Borkowski, Mater. Sci. Technol., 2010, 26, 1338-1344; (c) R. Sharma, P. A. Crozier, Z. C. Kang and L. Eyring, Philos. Mag., 2004, 84, 2731-2747; (d) M. E. Holtz, Y. Yu, J. Gao, H. D. Abruña and D. A. Muller, Microsc. Microanal., 2013, 19, 1027-1035.

3 (a) Q. Jeangros, A. Faes, J. B. Wagner, T. W. Hansen, U. Aschauer, J. Van herle, A. Hessler-Wyser and R. E. Dunin-Borkowski, Acta Mater., 2010, 58, 4578-4589; (b) J. A. Rodriguez, J. C. Hanson, A. I. Frenkel, J. Y. Kim and M. Perez, J. Am. Chem. Soc., 2002, 124, 346-354.

4 (a) B. Schaffer, W. Grogger and G. Kothleitner, Ultramicroscopy, 2004, 102, 27-36; (b) R. F. Egerton, Electron Energy-Loss Spectroscopy in the Electron Microscope, Springer, New York, 2011; (c) F. Hofer and P. Warbichler, Transmission Electron Energy Loss Spectrometry in Materials Science and The EELS Atlas, Wiley, 2005, pp. 159-222. 